\title{
Salinity and osmotic stress trigger different antioxidant responses related to cytosolic ascorbate peroxidase knockdown in rice roots
}

\author{
Juliana R. Cunha ${ }^{\mathrm{a}}$, Milton C. Lima Neto ${ }^{\mathrm{b}}$, Fabricio E.L. Carvalho ${ }^{\mathrm{a}}$, Marcio O. Martins ${ }^{\mathrm{a}}$, \\ Douglas Jardim-Messeder ${ }^{c}$, Marcia Margis-Pinheiro ${ }^{c}$, Joaquim A.G. Silveira, ${ }^{a}, *$
}

a Departamento de Bioquímica e Biologia Molecular, Universidade Federal do Ceará, Fortaleza, CEP 60451-970, Brazil

${ }^{\mathrm{b}}$ Campus do Litoral Paulista, Universidade Estadual Paulista (UNESP-CLP), São Vicente, CP - 73601 CEP 11380-972, Brazil

${ }^{\mathrm{c}}$ Departamento de Genética, Universidade Federal do Rio Grande do Sul, Porto Alegre, CEP 91501-970, Brazil

\section{A R T I C L E I N F O}

\section{Article history:}

Received 2 March 2016

Received in revised form 19 May 2016

Accepted 11 July 2016

Available online 12 July 2016

\section{Keywords:}

Ascorbate peroxidase

Ionic stress

Oryza sativa

Redox metabolism

Salt stress

\begin{abstract}
A B S T R A C T
Salinity and osmotic stress trigger distinct signals in roots, which might induce differences in antioxidant responses. To clarify these relationships, transgenic rice plants silenced in both cytosolic ascorbate peroxidases (apx1/2) and non-transformed (NT) were exposed to iso-osmotic concentrations of $\mathrm{NaCl}$ and mannitol. Under both stress conditions, apx1/2 roots did not suffer oxidative stress, revealing that cytosolic APXs were not crucial to oxidative protection. Silenced and non-transformed roots triggered different responses to high salinity and osmotic stress and these stressful factors induced also distinct antioxidant changes. High salinity up-regulated expression of important OsAPX isoforms and these changes were related to increased APX activity, especially in NT roots. Intriguingly, salt stress triggered up-regulation of OsCAT isoforms but CAT activity did not change in both genotypes. In contrast, mannitol trigged very low increment in expression of OSAPX isoforms but induced substantial up-regulation in APX activity in NT roots. Mannitol also remarkably up-regulated OSCATB expression in parallel to CAT activity, in both apx $1 / 2$ and NT roots. POD and GPX (glutathione peroxidases) activities were strongly increased by high salinity but did not change in response to mannitol, in both genotypes. The two stress types as well as apx1/2 and NT roots displayed different response in terms of modulation in the $\mathrm{H}_{2} \mathrm{O}_{2}$ levels but lipid peroxidation did not change. Membrane integrity was drastically affected by both stressful factors and similarly in both genotypes, whereas root fresh matter was affected only by salt stress. Altogether, the obtained data reveal that high salinity and osmotic stress trigger different antioxidant responses and these strategies were genotype-dependent. The different antioxidant molecular-biochemical mechanisms employed by cytosolic APX knockdown and non-transformed roots allowed reaching similar physiological performance.
\end{abstract}

(c) 2016 Elsevier B.V. All rights reserved.

\section{Introduction}

Plant roots play critical roles during growth and development, such as mineral nutrient uptake, maintenance of adequate plant water balance and hormone synthesis (Pierik and Testerink, 2014). Moreover, roots are intrinsically related to stress perception and signaling mechanisms connecting soil factors with whole plant metabolism (Choi et al., 2014). Soils are important sites of specific

\footnotetext{
* Corresponding author at: Departamento de Bioquímica e Biologia Molecular, Laboratório de Metabolismo de Plantas, Universidade Federal do Ceará, Av. Humberto Monte SN, Campus do Pici, Bl. 907, sl. 1080. Fortaleza, CEP 60451-970, Ceará, Brazil.

E-mail addresses: silveira@ufc.br, joaquim.silveira@cnpq.pesquisador.br (J.A.G. Silveira).
}

abiotic stresses, such as water deficit, high salinity, toxicity, nutrient deficiency, flooding etc. (Gupta et al., 1999; Małecka et al., 2001; Zhang and Zhang, 1994; Tabata et al., 2014). Most of these stressing factors have as a common characteristic the generation of a secondary stress related to disturbances in the redox metabolism (Adem et al., 2014). This secondary oxidative stress in roots is resultant from an unbalance between production and scavenging of reactive oxygen species (ROS) (Adem et al., 2014; Cavalcanti et al., 2007).

The mechanisms involved with generation and elimination of ROS in roots under high salinity and osmotic stress are scarcely known (Adem et al., 2014; Cavalcanti et al., 2007; Hernandez et al., 1993). High salinity has two components; ionic toxicity and osmotic and these elements might induce different types of responses in roots (Flowers et al., 2015; Munns and Gilliham, 2015; 
Roy et al., 2014). Both saline and osmotic agents might generate disturbances in root metabolism, including deleterious effects in several organelles and cellular compartments (Flowers et al., 2015; Zhu, 2002). These alterations might affect especially the cell wall, apoplast, cytosol and mitochondria, inducing changes in gene expression and enzyme activities related to redox metabolism (Maia et al., 2013). Under these conditions, frequently the production of ROS is over increased and the antioxidant mechanisms might be insufficient to re-establish a favorable redox homeostasis (Foyer and Noctor, 2015).

The molecular-biochemical mechanisms involved with root perception of signals from saline ions and osmotic stress are complex and still poorly understood (Choi et al., 2014). After perception and signal transduction in cytosol, a cascade of reactions occurs until the expression of different stress-related genes (Maathuis, 2014). These genes encode for several important proteins including those associated with root growth and ROS scavenging (Mittova et al., 2004). ROS production in roots might occur from biochemical and chemical processes such as HaberWeiss-Fenton reactions (Halliwell and Foyer, 1976), excess energy in mitochondrial electron transport chain - ETC (Møller, 2001), upregulation of NADPH oxidase in plasmalemma (Passardi et al., 2004 ) and alterations in the cytosolic ascorbate-glutathione cycle (Munné-bosch et al., 2013).

Salt and osmotic stresses might induce down- or upregulation in the expression of genes that encode for catalases (CAT), ascorbate peroxidases (APX) and glutathione peroxidases (GPX) and type III peroxidases (POD) (Hong et al., 2009, 2007; Mittova et al., 2004). APX and CAT are the most important peroxidases responsible for scavenging and maintaining of $\mathrm{H}_{2} \mathrm{O}_{2}$ in levels adequate to redox homeostasis in roots (Cavalcanti et al., 2007). Rice has eight APX isoforms, viz. two localized in mitochondria, two in cytosol, two in chloroplast and two in peroxisomes (Teixeira et al., 2006, 2004). The cytosolic APX isoforms in plants are found in high concentrations and these enzymes are strongly involved in protection against abiotic stress in leaves (Shigeoka and Maruta, 2014). These enzymes are the most important members of APX family in antioxidant protection (Shigeoka and Maruta, 2014).

The role and importance of cytosolic APX isoforms as well as its relationships with other peroxidases in root redox metabolism is incipient (Maia et al., 2013). The antioxidant metabolism in roots, especially in response to ionic toxicity and osmotic stress, is much less studied compared to leaves. The majority of published articles concerning the saline and osmotic stress responses in roots are descriptive and the underlying mechanisms involving the role of each specific antioxidant are poorly understood (Cavalcanti et al., 2007; de Azevedo Neto et al., 2006; Maia et al., 2013). For instance, which is the importance of cytosolic APXs and CAT in scavenging and maintaining of $\mathrm{H}_{2} \mathrm{O}_{2}$ homeostasis in roots exposed to acute salinity and osmotic stress? In addition, which is the role, complementary or primary, of other peroxidases such as CAT, POD and GPX in such processes? Undoubtedly, the knowledge on redox metabolism generated from leaf studies would not be extensible for roots since that these organs present very different structures related to oxidative and antioxidant metabolism.

We hypothesized here that high salinity and osmotic stress trigger different antioxidant responses in rice roots and these differences also are distinct among cytosolic APXs deficient (knockdown) and non-transformed rice roots. This study revealed that ionic and osmotic stress triggered very different antioxidant responses represented by the differential modulation in OsAPX and OsCAT expression and regulation of APX, CAT, GPX and POD activities. The role of $\mathrm{H}_{2} \mathrm{O}_{2}$ in these responses and the physiological significance in terms of oxidative in roots is discussed.

\section{Materials and methods}

\subsection{Construction of the plant vector and plant transformation}

The non-transformed (NT) and transgenic (apx1/2) rice (Oryza sativa L. cv. Nipponbare) plants were obtained as previously reported by Rosa et al. (2010). Chimerical gene producing mRNA with a hairpin structure (hpRNA) was constructed based on the sequence of the OsAPX1 (LOC_Os03g17690) and OsAPX2 (LOC_Os07g49400) genes. The following primer pairs were used: CGCCGCCAACGCCGGCCTCGA and CACTCAAACCCATCTGCGCA (OSAPX1/2RNAi). PCR products were cloned into the Gateway vector (pANDA), in which hairpin RNA is driven by a maize ubiquitin promoter and an intron that is placed $50 \mathrm{bp}$ upstream of inverted repeats (Miki and Shimamoto, 2004). Agrobacterium mediated transformation was performed as described previously (Rosa et al., 2010). After an initial screening involving 15 lines, three were selected (apx1/2-5, apx1/2-10 and apx1/2-11). These lines showed similar molecular and physiological characteristics (Rosa et al., 2010). Previously (Bonifacio et al., 2011), and in this study, the apx1/2-5 line was used, at the F3 generation, as a representative mutant of the apx1/2 double-silenced lines. These plants have exhibited a similar response in terms of OsAPX1/21 and OsAPX2 transcript amount and APX activity in leaves at F1, F2 and F3 generations (Bonifacio et al., 2011).

\subsection{Plant growth and treatments}

apx1/2 and the NT seedlings (7-day-old) were transferred to $3 \mathrm{~L}$ plastic pots filled with half-strength Hoagland-Arnon's nutritive solution (Hoagland and Arnon, 1950). The pH was adjusted to $6.0 \pm 0.5$ every two days, and the nutrient solution was changed weekly. The plants were grown for 45 days in a greenhouse under natural conditions as follow: day/night mean temperature of 29/ $24^{\circ} \mathrm{C}$, mean relative humidity of $68 \%$, and a photoperiod of $12 \mathrm{~h}$. The light intensity inside the greenhouse varied as a typical day from 6:00 a.m. to 6:00 p.m., reaching an average of maximum PPFD equals to $820 \mu \mathrm{mol} \mathrm{m}^{-2} \mathrm{~s}^{-1}$ at noon. NT and apx1/2 plants were grown in nutrient solution supplied with $\mathrm{NaCl}$ and mannitol, which were used in iso-osmotic concentrations corresponding to $-0.62 \mathrm{MPa}$. The osmolality was measured in a vapour pressure osmometer (Model 5520, Wescor ${ }^{\circledR}$, USA) and the final concentrations of $\mathrm{NaCl}$ and mannitol were adjusted to $150 \mathrm{mM}$ and $268 \mathrm{mM}$, respectively. The nutrient solution without these two solutes was used as control. $\mathrm{NaCl}$ and mannitol were added to the nutrient solution in two steps (half of each solute per day) to avoid osmotic shock. Plants were subjected to these stressful conditions for eight days. Subsequently, $5 \mathrm{~cm}$ from the superior part of mature rice roots were immediately harvested, frozen in liquid $\mathrm{N}_{2}$ and stored at $-80^{\circ} \mathrm{C}$ until the biochemical and transcript analyses.

\section{3. $\mathrm{Na}^{+}$and $\mathrm{K}^{+}$content determinations}

The $\mathrm{Na}^{+}$and $\mathrm{K}^{+}$contents in roots were determined as previously described (Marques et al., 2013). Lyophilized root samples were transferred to hermetically sealed tubes containing deionized water. Subsequently, the samples were boiled in water bath at $100^{\circ} \mathrm{C}$ for $1 \mathrm{~h}$. After extract filtration using filter paper, the $\mathrm{Na}^{+}$and $\mathrm{K}^{+}$contents were determined by flame photometry (B462, Micronal $^{\circledR}$, Brazil).

\section{4. $\mathrm{H}_{2} \mathrm{O}_{2}$ concentration, membrane damage (electrolyte leakage) and lipid peroxidation (TBARS content)}

Hydrogen peroxide content was measured using the Amplex ${ }^{\mathbb{R}}$ red kit (Thermo Fisher Scientific ${ }^{\circledR}$, USA), based on colorimetric 
measure of resorufin formation in presence of $\mathrm{H}_{2} \mathrm{O}_{2}$ (Zhou et al., 1997). Fresh root samples were macerated with liquid $N_{2}$ in the presence of $100 \mathrm{mM}$ K-phosphate buffer $\mathrm{pH} 7.5$ and centrifuged at $12,000 \times \mathrm{g}\left(4^{\circ} \mathrm{C}\right)$ during $30 \mathrm{~min}$. The supernatant was immediately used for $\mathrm{H}_{2} \mathrm{O}_{2}$ determination. The measurements were performed after reading at $560 \mathrm{~nm}$. The hydrogen peroxide content was calculated from a standard curve, and the results were expressed as nmol $\mathrm{H}_{2} \mathrm{O}_{2} \mathrm{~g}^{-1}$ fresh weight (FW). Cellular integrity (electrolyte leakage) was measured as described by Blum and Ebercon, (1981). Root samples (middle portion) were placed in tubes containing deionized water. The flasks were incubated in a shaker for $12 \mathrm{~h}$, and the electric conductivity in the medium (L1) was measured. Then, the medium was boiled $\left(95^{\circ} \mathrm{C}\right)$ for $60 \mathrm{~min}$ and the electric conductivity (L2) was measured again. The relative membrane damage $(\mathrm{MD})$ was estimated by $\mathrm{MD}=\mathrm{L} 1 / \mathrm{L} 2 \times 100$. Lipid peroxidation was measured based on the formation of thiobarbituric acidreactive substances (TBARS) in accordance with Cakmak and Horst, (1991). The concentration of TBARS was calculated using its absorption coefficient $\left(155 \mathrm{mM}^{-1} \mathrm{~cm}^{-1}\right)$, and the results were expressed as nmol MDA-TBA $\mathrm{g} \mathrm{FW}^{-1}$.

\subsection{Quantitative real-time RT-PCR ( $q R T-P C R)$}

qRT-PCR experiments were carried out using cDNA synthesized from roots total RNA and purified with Trizol (Invitrogen ${ }^{\circledR}$, USA) as previously described (Rosa et al., 2010). Pairs of primers to amplify the Osfdh3 gene (LOC_Os02g57040) and the Osfa1 gene (LOC_Os03g08020) were used as internal controls to normalize the amount of mRNA present in each sample. All qRT-PCR reactions were performed with a StepOne plus ${ }^{\mathrm{TM}}$ Real-Time PCR system (Applied Biosystems ${ }^{\circledR}$, USA) using SYBR-green intercalating dye fluorescence for detection.

\subsection{Protein extraction and enzyme activity assays}

For preparation of enzymatic extracts, fresh root samples were ground to a fine powder in the presence of liquid $\mathrm{N}_{2}$ using a mortar and pestle and extracted in ice-cold $\left(4{ }^{\circ} \mathrm{C}\right)$ and $100 \mathrm{mM} \mathrm{K}$ phosphate buffer ( $\mathrm{pH} 7.0$ ) containing $0.1 \mathrm{mM}$ EDTA and $2 \mathrm{mM}$ ascorbic acid (to prevent APX denaturation). The homogenate was centrifuged at $15,000 \mathrm{xg}$ for $30 \mathrm{~min}$, and the obtained supernatant was used for determination of all enzymatic activities: catalase (CAT; EC 1.11.1.6); ascorbate peroxidase (APX; EC 1.11.1.11); glutathione peroxidase (GPX; EC 1.11.1.9) and type III peroxidase (POD; EC 1.11.1.7). All steps were performed under low temperature $\left(2-4^{\circ} \mathrm{C}\right)$. The protein content was measured by Bradford method (Bradford, 1976), utilizing BSA as a standard.

CAT activity was measured following the oxidation of $\mathrm{H}_{2} \mathrm{O}_{2}$ at $240 \mathrm{~nm}$. CAT was determined after the reaction of the enzymatic extract in the presence of $50 \mathrm{mM}$ potassium phosphate buffer $(\mathrm{pH}$ 7.0) containing $20 \mathrm{mM} \mathrm{H}_{2} \mathrm{O}_{2}$. The reaction took place at $30^{\circ} \mathrm{C}$ with the absorbance monitored at $240 \mathrm{~nm}$ over $300 \mathrm{~s}$ (Havir and McHale, 1987). CAT activity was calculated using the molar extinction coefficient of $\mathrm{H}_{2} \mathrm{O}_{2}\left(40 \mathrm{M}^{-1} \mathrm{~cm}^{-1}\right)$ and was expressed as $\mu \mathrm{mol} \mathrm{H}_{2} \mathrm{O}_{2}$ $\mathrm{mg}^{-1}$ protein $\mathrm{min}^{-1}$. APX activity was assayed in a reaction mixture containing $0.5 \mathrm{mM}$ ascorbate and $0.1 \mathrm{mM}$ EDTA dissolved in $100 \mathrm{mM}$ K-phosphate buffer ( $\mathrm{pH} 7.0$ ) and enzyme extract. The

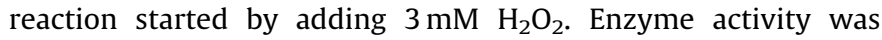
measured by following the decrease in absorbance at $290 \mathrm{~nm}$ $\left(25^{\circ} \mathrm{C}\right.$ ) over $180 \mathrm{~s}$ (Nakano and Asada, 1981). APX activity was calculated from the ASC molar extinction coefficient $\left(2.8 \mathrm{mM}^{-1}\right.$ $\mathrm{cm}^{-1}$ ) and activity was expressed as $\mu \mathrm{mol}$ ASC $\mathrm{mg}^{-1}$ protein $\min ^{-1}$. GPX activity was measured according to the method of
Awasthi et al. (1975). To perform the enzymatic assay, the extract were mixed in a reaction medium containing K-phosphate buffer $100 \mathrm{mM}, \mathrm{pH} 7.0,4 \mathrm{mM} \mathrm{GSH}, 0.2 \mathrm{mM} \mathrm{NADPH}$ and $0.05 \mathrm{U}$ of Glutathione Reductase (type II from wheat, Sigma-Aldrich ${ }^{\circledR}$, USA). The reaction was initiated by addition of cumene hydroperoxide. GPX activity was determined by the decrease of NADPH absorption at $340 \mathrm{~nm}$. The non-specific NADPH decrease was corrected using the same medium free of cumene hydroperoxide. The GPX activity was estimated from the molar extinction coefficient of NADPH $\left(6.22 \mathrm{mM}^{-1} \mathrm{~cm}^{-1}\right)$ and expressed as nmol $\mathrm{NADPH} \mathrm{mg}^{-1}$ protein $\mathrm{min}^{-1}$. POD activity was assayed by measuring the rate of guaiacol oxidation using the method of Amako et al. (1994). The reaction medium consisted of $50 \mathrm{mM} \mathrm{K}$ phosphate buffer ( $\mathrm{pH} 7.0$ ), $20 \mathrm{mM}$ guaiacol as an electron donor and $0.1 \mathrm{mM}$ hydrogen peroxide. The reaction product intensity was measured in spectrophotometer at $430 \mathrm{~nm}$. POD activity was estimated utilizing the molar extinction coefficient of tetraguaiacol $\left(26.6 \mathrm{mM}^{-1} \mathrm{~cm}^{-1}\right)$ and was expressed as $\mu \mathrm{mol}$ tetraguaiacol $\mathrm{mg}^{-1}$ protein $\mathrm{min}^{-1}$.

\subsection{Western blotting of cytosolic APX proteins}

Root protein extracts were first separated by SDS-PAGE (Laemli, 1970). Equal amounts of protein $(20 \mu \mathrm{g})$ were electrophoretically transferred to a nitrocellulose membrane (Towbin et al., 1979). Polypeptide detection was performed using specific polyclonal antibodies against APX (Agrisera $\odot$, Sweden). Membranes were blocked overnight with $5 \%$ non-fat milk in saline Tris- $\mathrm{HCl}$ buffer ( $100 \mathrm{mM}$ Tris- $\mathrm{HCl}, \mathrm{pH} 7.6,150 \mathrm{mM} \mathrm{NaCl}, 0.05 \%$ Tween-20), incubated with secondary antibodies conjugated with peroxidase (Agrisera $\odot$, Sweden) and developed using a chemiluminescent detection ECL standard reagents system ${ }^{\mathbb{R}}$ (GE Healthcare, USA). All the procedure was realized according manufacturer's manual.

\subsection{Statistical analyses and experimental design}

The experiment was arranged in a completely randomized design in a $2 \times 3$ factorial: two genotypes (NT and apx1/2) and three treatments (control, $\mathrm{NaCl}$ and mannitol), with four independent replicates. An individual pot containing 2 plants represented each replicate. Data were analyzed using ANOVA, and the means were compared using the Tukey's test at a confidence level of 0.05 .

\section{Results}

\subsection{Phenotypic characterization, OsAPX1 and OsAPX2 transcripts,} protein abundance and APX activity in silenced roots under control condition

The 45-day-old cytosolic APX silenced rice plants (apx1/2) did not exhibit any apparent phenotypic changes in their root morphology and fresh matter, compared to NT plants (Fig. S1A and B). It is important to note that in roots the silencing intensity of both APX1 and APX2 was similar to those previously observed in rice leaves (Carvalho et al., 2014). Indeed, the amount of both OsAPX1 and OsAPX2 mRNAs were efficiently targeted by the hairpin construct, drastically reducing their accumulation by approximately 90\% (Fig. 1A). In addition, western blotting analysis revealed a complete absence of both APX1 and APX2 proteins compared to NT (Fig. 1B) and APX activity was notably decreased by $66 \%$ in relation to NT (Fig. 1C). These results strongly suggest that the two cytosolic APXs played an insignificant importance for 

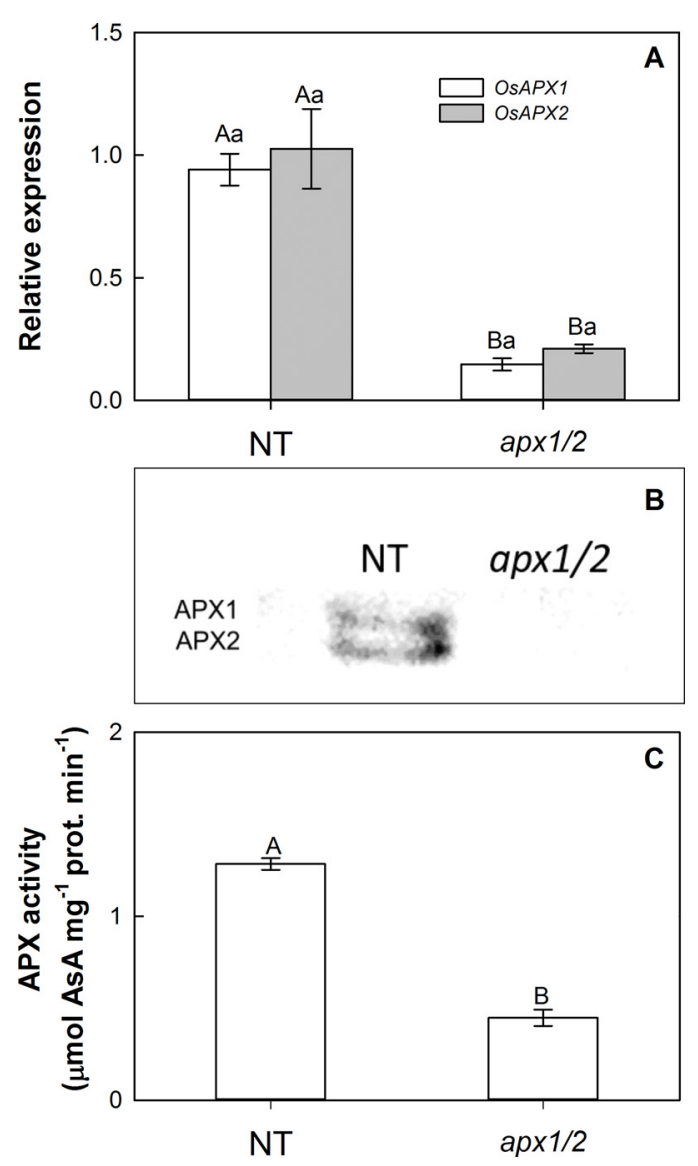

Fig. 1. Transcript levels of OsAPX1 and OsAPX2 (A), APX1 and APX2 western blotting (B) and APX activity in roots of NT and $A P X 1 / 2$ plants grown in nutrient solution for 45 days. Different capital letters represent significant differences among the NT and apx1/2 plants within different treatments whereas different lowercase letters represent significant differences between treatments, within genotypes. Data are means of four replicates $( \pm \mathrm{SD}$ ) and the averages were compared using the Tukey's test, at a confidence of 0.05 . The relative expression of each APX locus was normalized by the average value obtained from the NT control plants.

normal growth and development of rice roots under control condition.

3.2. High salinity caused drastic effects on root growth and cellular integrity but these effects were not aggravated by apx1/2 deficiency

NT and apx1/2 plants were exposed to high salinity ( $\mathrm{NaCl}$ $150 \mathrm{mM}$ ) for eight days to examine the cumulative effects induced by osmotic and ionic toxicity components in rice roots. Salt stress caused drastic effects on the growth (fresh matter accumulation) in both shoot (Fig. S1C-D) and roots (Table S1). These detrimental effects produced by $\mathrm{NaCl}$ were similar in NT and transgenic plants deficient in both cytosolic APXs. Both studied plants showed high $\mathrm{Na}^{+}$content in roots in response to $\mathrm{NaCl}$ treatment but these values were higher in silenced rice. The $\mathrm{Na}^{+} / \mathrm{K}^{+}$ratios were relatively high in both salt-treated genotypes (from 2.0 in apx $1 / 2$ to 2.5 in $\mathrm{NT}$ ), indicating the occurrence of osmotic stress followed by $\mathrm{Na}^{+}$toxicity in roots (Table S1). Corroborating these results, both genotypes suffered strong and similar increase in root membrane damage (electrolyte leakage), corresponding to an increase of approximately two-fold in relation to control (Table S1).
3.3. High salinity up-regulated transcript amounts of APX1 and APX2, and stimulated APX activity and did not induce oxidative stress in both $N T$ and apx $1 / 2$ roots

High salinity triggered up-regulation in mRNAs of both APX1 and APX2 in NT plants and the increase was higher in this late isoform. Unexpectedly, a similar effect was observed in silenced apx $1 / 2$ line, despite of the effectiveness of the hairpin to inhibit apx1/2 transcription in control conditions (Fig. 2A and B). APX activity also was stimulated by high salinity in both genotypes but apx $1 / 2$ roots displayed higher increase ( $150 \%$ in relation to control), whereas in NT plants the activity increased $40 \%$ compared to control condition (Fig. 2C). Despite the strong salt-induced increase in APX activity of silenced plants, the final reached activity in both treatments was lower than that presented by NT plants. Although drastic intensity of salt stress, the TBARS contents, an indicator of lipid peroxidation, did not change in both genotypes (Fig. 3A). It is important to note that the silencing triggered a prominent increase in $\mathrm{H}_{2} \mathrm{O}_{2}$ content, under control conditions (Fig. 3B). In opposition, the $\mathrm{H}_{2} \mathrm{O}_{2}$ content decreased in both NT and apx $1 / 2$ plants, but more intensely (by $50 \%$ ) in silenced roots, in response to high salinity. Nevertheless, this salt-induced reduction was enough to return to the initial $\mathrm{H}_{2} \mathrm{O}_{2}$ levels displayed by silenced roots to values around of those showed by NT plants under $\mathrm{NaCl}$-treated condition (Fig. 3B).

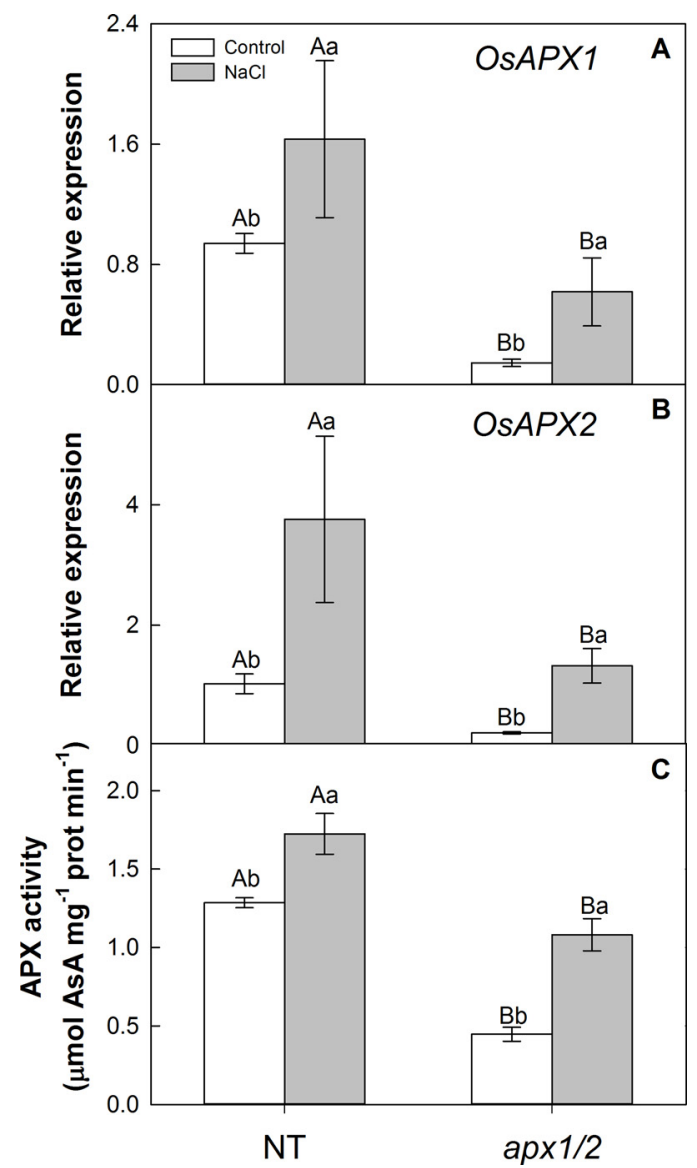

Fig. 2. Transcript levels of $O S A P X 1$ (A) and OsAPX2 (B) and APX activity (C) in roots of NT and apx1/2 plants exposed to $\mathrm{NaCl}(150 \mathrm{mM}, \Psi \mathrm{S}=-0.62 \mathrm{MPa})$ solution for eight days. Different capital letters represent significant differences among the NT and apx1/2 plants within different treatments whereas different lowercase letters represent significant differences between treatments, within genotypes. Data are means of four replicates $( \pm \mathrm{SD})$ and the averages were compared using the Tukey's test, at a confidence of 0.05 . The relative expression of each APX locus was normalized by the average value obtained from the NT control plants. 


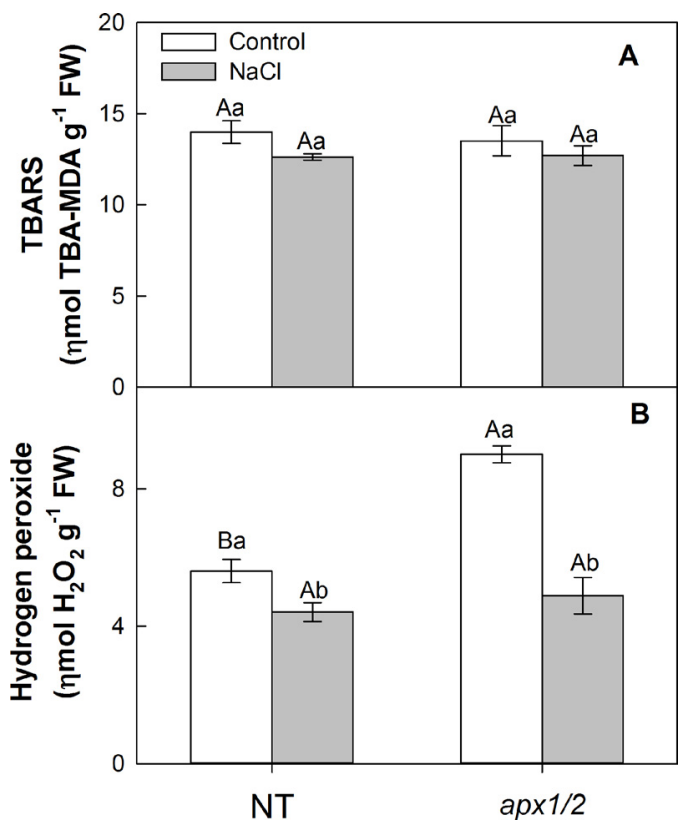

Fig. 3. Changes in TBARS (A) and hydrogen peroxide content (B) in roots of NT and apx1/2 plants exposed to $\mathrm{NaCl}(150 \mathrm{mM}, \Psi \mathrm{s}=-0.62 \mathrm{MPa})$ solution for eight days. Different capital letters represent significant differences among the NT and apx1/2 plants within different treatments whereas different lowercase letters represent significant differences between treatments, within genotypes. Data are means of four replicates $( \pm \mathrm{SD})$ and the averages were compared using the Tukey's test, at a confidence of 0.05 .

\subsection{High salinity strongly up-regulated others OsAPX and OsCAT} transcripts but did not alter CAT activity in both genotypes

The APX1/2 silencing triggered slight changes in the expression of other OsAPX isoforms in roots, exception for OsAPX8, which was up-regulated by 5.6-fold compared to NT control. In opposition, high salinity induced strong up-regulation in important APX genes in NT plants such as the peroxisomal OsAPX3 (60-fold), mitochondria OsAPX5 (23-fold) and plastidial/chloroplastic OsAPX8 (106fold). Others (peroxisomal OsAPX4 and mitochondria OsAPX6) were up-regulated in a minor extent, 3.8- and 4.42-fold, respectively. The effects of salt stress in silenced plants were minor: OsAPX3 (5fold), OsAPX4 (5-fold), OsAPX5 (4-fold) and OsAPX8 (4.2-fold), all compared to NT control (Fig. 4). These results indicate that saltinduced up-expression of other APX transcripts, jointly to OsAPX1 and OsAPX2, could had contributed intensely to increase APX activity in both root genotypes. Rice silencing triggered upregulation in OsCATA and OsCATB mRNAs, which was strongly

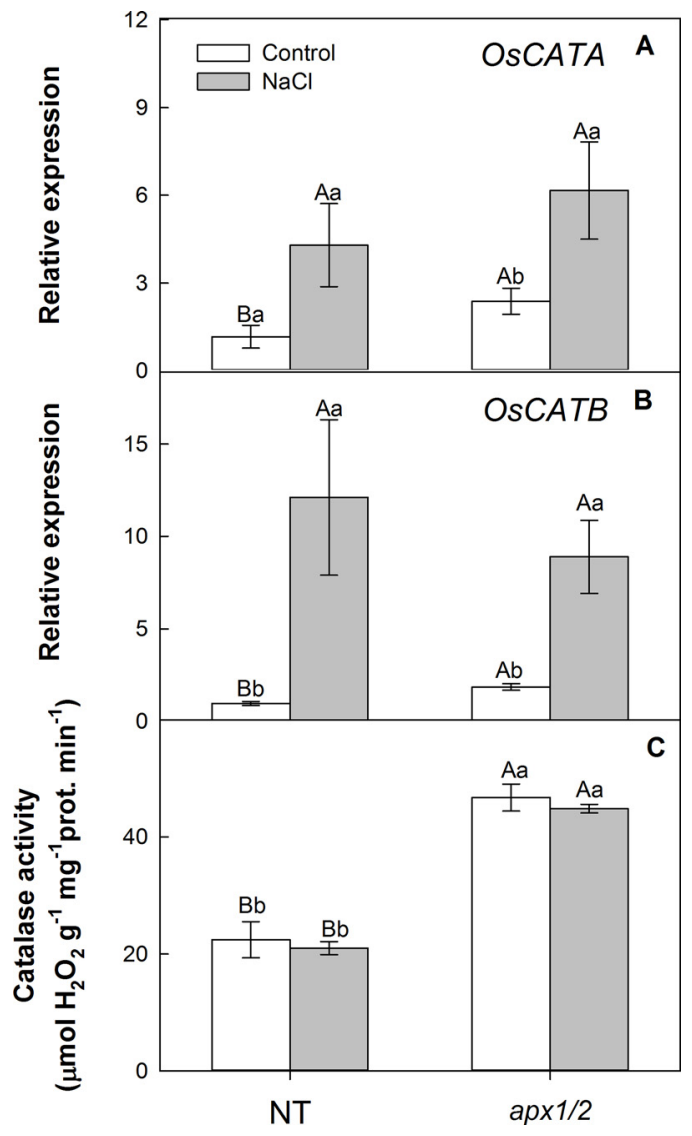

Fig. 5. Transcript levels of OsCATA (A) and OsCATB (B) and CAT activity (C) in roots of NT and apx1/2 plants exposed to $\mathrm{NaCl}(150 \mathrm{mM}, \Psi \mathrm{s}=-0.62 \mathrm{MPa})$ solution for eight days. Different capital letters represent significant differences among the NT and apx1/2 plants within different treatments whereas different lowercase letters represent significant differences between treatments, within genotypes. Data are means of four replicates $( \pm \mathrm{SD})$ and the averages were compared using the Tukey's test, at a confidence of 0.05 . The relative expression of each APX locus was normalized by the average value obtained from the NT control plants.

related to increase in CAT activity, compared to NT in control condition (Fig. 5). NaCl induced significant up-regulation in OsCATA and OSCATB transcript amounts, compared to NT control, but CAT activity did not change in roots of both genotypes. In compensation to CAT activity, POD and GPX activities were significant and similarly increased by salt stress and that increment was higher in POD activity (Table 1). Apparently, in response to increased salinity, the activities of APX, GPX and POD are more important to

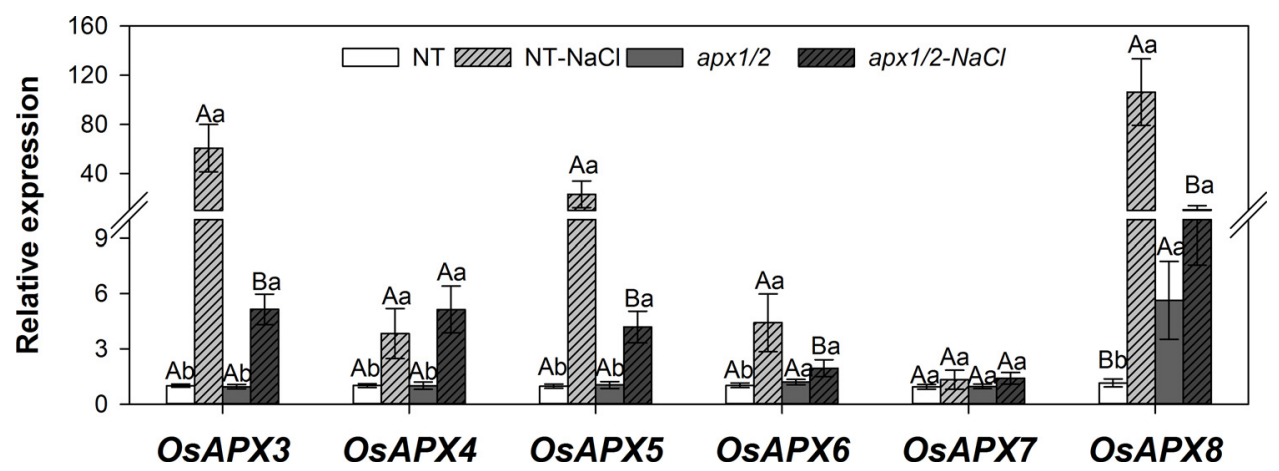

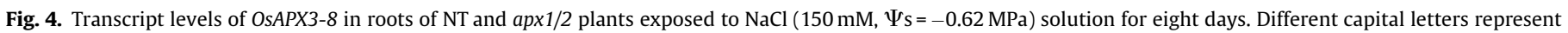

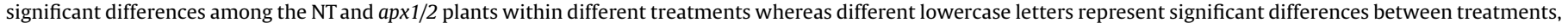

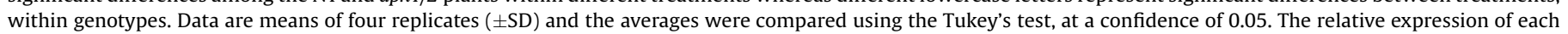
OsAPX locus was normalized by the average value obtained from the NT control plants. 
Table 1

Changes in POD activity (A) and GPX activity (B) in roots of NT and apx1/2 plants exposed to $\mathrm{NaCl}(268 \mathrm{mM}, \Psi \mathrm{s}=-0.62 \mathrm{MPa})$ or mannitol $\left(\Psi_{\mathrm{s}}=-0.62 \mathrm{MPa}\right)$ solution for eight days. Different capital letters represent significant differences among the NT and apx $1 / 2$ plants within different treatments whereas different lowercase letters represent significant differences between treatments, within genotypes. Data are means of four replicates and the averages were compared using the Tukey's test, at a confidence of 0.05 .

\begin{tabular}{|c|c|c|c|c|c|c|}
\hline \multirow[t]{3}{*}{ Parameters } & \multicolumn{6}{|c|}{ Rice lines } \\
\hline & \multicolumn{3}{|l|}{ NT } & \multicolumn{3}{|l|}{ apx1/2 } \\
\hline & Control & $\mathrm{NaCl}$ & Mannitol & Control & $\mathrm{NaCl}$ & Mannitol \\
\hline POD activity & $7.6 \mathrm{Bb}$ & 11.7Aa & $7.6 \mathrm{Bb}$ & $10.1 \mathrm{Ab}$ & $12.6 \mathrm{Aa}$ & $10.3 \mathrm{Ab}$ \\
\hline GPX activity & $6.3 \mathrm{Ab}$ & $12.5 \mathrm{Aa}$ & $6.4 \mathrm{Ab}$ & 5.7Aa & $12.8 \mathrm{Aa}$ & $4.9 \mathrm{Bb}$ \\
\hline
\end{tabular}

a $\mu \mathrm{mol} \mathrm{H} \mathrm{O}_{2} \mathrm{mg}^{-1}$ prot $\mathrm{min}^{-1}$.

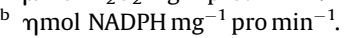

$\mathrm{H}_{2} \mathrm{O}_{2}$ scavenging and homeostasis maintaining than CAT, in both NT and silenced rice roots.

\subsection{Mannitol did not cause change in root growth and lipid} peroxidation associated to contrasting responses of CAT, POD and GPX activities in both genotypes

In contrast to $\mathrm{NaCl}$, mannitol did not change the root $\mathrm{FM}$ in both NT and apx1/2 genotypes (Table S1, Fig. S1E-F). Both OsAPX1 and OsAPX2 transcript amounts were up-regulated by mannitol in NT

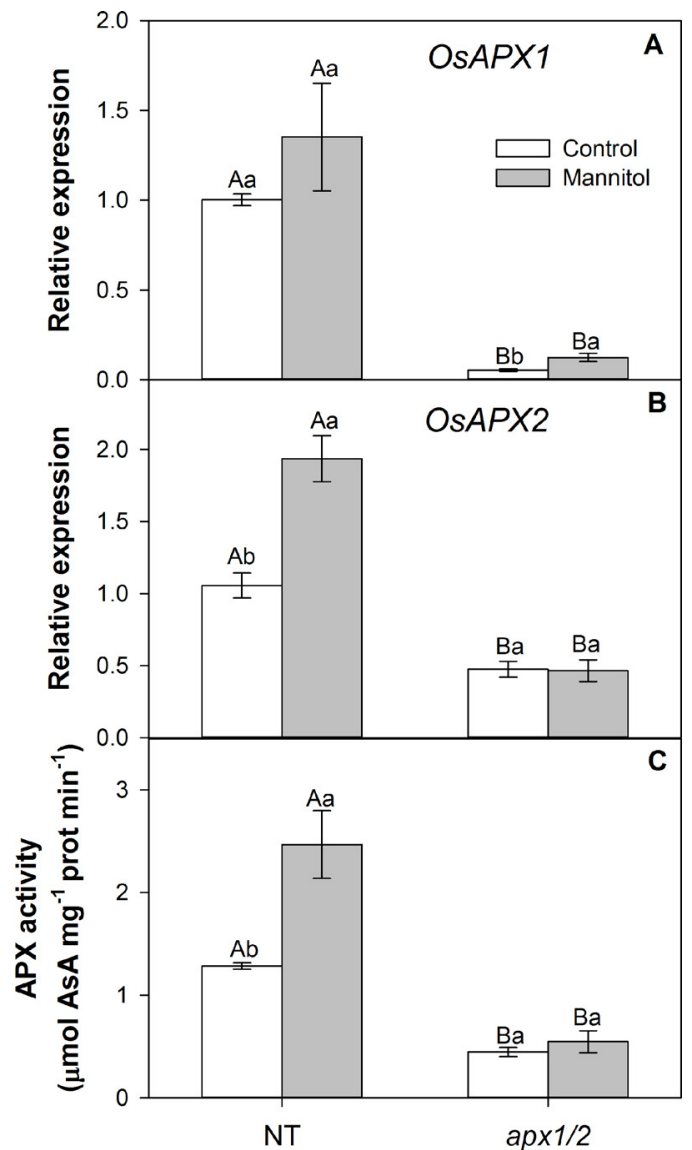

Fig. 6. Transcript levels of OsAPX1 (A) and OsAPX2 (B) and APX activity (C) in roots of NT and apx $1 / 2$ plants exposed to mannitol $(268 \mathrm{mM}, \Psi \mathrm{s}=-0.62 \mathrm{MPa})$ solution for eight days. Different capital letters represent significant differences among the NT and apx1/2 plants within different treatments whereas different lowercase letters represent significant differences between treatments, within genotypes. Data are means of four replicates $( \pm \mathrm{SD})$ and the averages were compared using the Tukey's test, at a confidence of 0.05 . The relative expression of each APX locus was normalized by the average value obtained from the NT control plants.

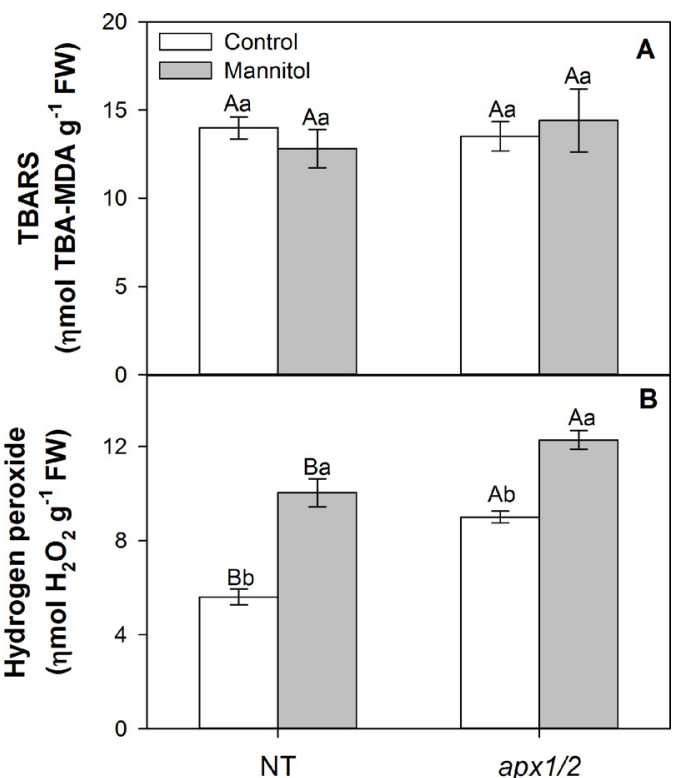

Fig. 7. Changes in TBARS (A) and hydrogen peroxide content (B) in roots of NT and apx1/2 plants exposed to mannitol $\left(268 \mathrm{mM}, \Psi_{\mathrm{S}}=-0.62 \mathrm{MPa}\right)$ solution for eight days. Different capital letters represent significant differences among the NT and apx1/2 plants within different treatments whereas different lowercase letters represent significant differences between treatments, within genotypes. Data are means of four replicates $( \pm \mathrm{SD})$ and the averages were compared using the Tukey's test, at a confidence of 0.05 .

but the late was much more over-regulated whereas OsAPX1 and OsAPX2 transcript levels remained very low and unchanged in apx1/2 silenced roots in both control and mannitol conditions, compared to NT control (Fig. 6A and B). APX activity was strongly up-regulated by mannitol in NT and OSAPX2 expression exhibited a similar response in both genotypes (Fig. 6C). Moreover, NT and apx1/2 roots did not exhibit changes in TBARS levels in response to mannitol, similar to that previously noticed for salt stress (Fig. 7A). In opposition to the noticed for high salinity, mannitol induced a remarked increase in the $\mathrm{H}_{2} \mathrm{O}_{2}$ content in both genotypes (Fig. 7B).

Mannitol triggered up-regulation of some OSAPX transcripts in both genotypes, particularly OsAPX3 and OsAPX8. The increase in the transcript amounts for NT and apx1/2 were approximately and respectively: OsAPX3 2- and 5-fold; OsAPX4 2- and 2-fold and OsAPX8 2.5- and 12-fold (Fig. 8). It is interesting to note that the silencing triggered significant up-regulation (in control condition) in only OsAPX8 (by 5.6-fold), all in comparison to NT control. NTmannitol treated plants exhibited a strong up-regulation (by 12fold) in OsAPX8 compared with NT control. In addition, OsCATA transcripts were slightly up-regulated by mannitol in NT, whereas in apx $1 / 2$ plants they significantly decreased. In contrast, OsCATB mRNA amounts increased in both genotypes, but the increment was higher in NT than in silenced plants (Fig. 9A and B). CAT activity strongly increased in both genotypes in response to mannitol, showing a trend very similar to OSCATB transcripts (Fig. 9C). In addition, differently from CAT, both POD and GPX activities did not change by effect of osmotic stress induced by mannitol and these responses were very contrasting to that displayed by these three enzymes in responses to high salinity (Table 1). In summary, high salinity and osmotic stress were able to differently trigger antioxidant mechanisms in rice roots. These responses allowed the plants to maintain adequate $\mathrm{H}_{2} \mathrm{O}_{2}$ levels and avoid oxidative stress, even when both cytosolic APXs were silenced (Fig. 10; Fig. S2). 


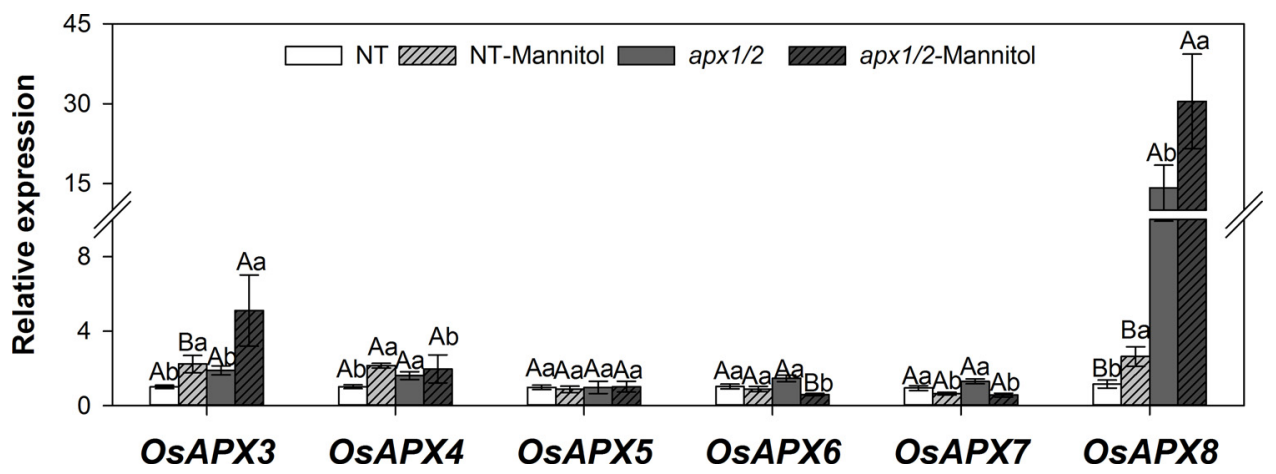

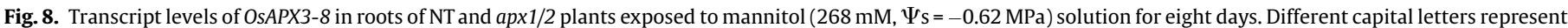

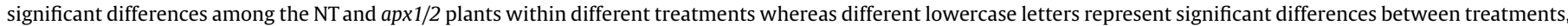

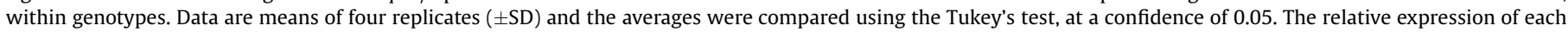
OSAPX locus was normalized by the average value obtained from the NT control plants.

\section{Discussion}

The data reported here strongly evidenced that high salinity $(\mathrm{NaCl})$ and mannitol triggered contrasting antioxidant response in rice roots, regardless of deficiency in cytosolic APXs. Interestingly, despite these differences, both stressful factors induced similar effects on membrane damage and lipid peroxidation in the two genotypes. These results clearly evidence that oxidative protection in rice roots against those stresses might involve redundant molecular and biochemical mechanisms as has been widely reported (Bonifacio et al., 2011; Miller et al., 2007; Rizhsky et al., 2002; Rosa et al., 2010; Carvalho et al., 2014; Sousa et al., 2015). Moreover, our data also show clearly that deficiency in both cytosolic APXs (APX1 and APX2) is less important or even insignificant for $\mathrm{H}_{2} \mathrm{O}_{2}$ scavenging and oxidative protection in cytosol of rice roots. These results are unexpected, once that is amply reported that these enzymes are essential to scavenging and homeostasis maintaining of $\mathrm{H}_{2} \mathrm{O}_{2}$ in leaves of some species (Davletova et al., 2005; Pnueli et al., 2003; Shigeoka and Maruta, 2014).

The presented data highlight that $\mathrm{NaCl}$ and mannitol should have triggered different signals to rice roots, which could have induced distinct perception, transduction and gene expression (Choi et al., 2014; Zhu, 2002). These genes could have encoded for differential expression of APX, CAT, POD and GPX enzymes (Foyer and Noctor, 2005), which might have acted in a redundant way, and differently for each genotype. It is interesting to note that the two stressful agents differently modulated the $\mathrm{H}_{2} \mathrm{O}_{2}$ levels and these responses were genotype-dependent. Thus, it is plausible to argue that this molecule can have acted as a signal, mediating the expression of genes linked to synthesis of those peroxidases (Corpas, 2015; Liu et al., 2010; Petrov and Van Breusegem, 2012; Sewelam et al., 2014). Indeed, a consensus has been established in literature that $\mathrm{H}_{2} \mathrm{O}_{2}$ is a powerful signaling molecule involved in expression of several defense genes against abiotic stress, particularly some peroxidases such as those studied here (Liu et al., 2010; Munné-bosch et al., 2013; Sewelam et al., 2014).

In this current study, $\mathrm{H}_{2} \mathrm{O}_{2}$ might have played a central role in antioxidant response to high salinity and osmotic stress in order to signal for different antioxidant response in rice roots. It is interesting to note that salt stress induced a prominent decrease in $\mathrm{H}_{2} \mathrm{O}_{2}$ content in silenced roots but did not change it in NT. In contrast, the content of this ROS was increased by mannitol in both genotypes. These responses were associated with differences in the expression of OsAPX and OsCAT isoforms and activities of the studied peroxidases in the two genotypes. These results suggest that $\mathrm{H}_{2} \mathrm{O}_{2}$ might have acted as a signaling for these different responses, which are stress and genotype dependent. Actually, in a previous study with cowpea roots, we have proposed that salt and drought stress conditions trigger distinct oxidative modulation, which involves activities of apoplastic class III peroxidases (POD) and APX (Maia et al., 2013). Indeed, under salt stress conditions, a strong decrease in APX activity and $\mathrm{H}_{2} \mathrm{O}_{2}$ concentration is inversely correlated to cell-wall POD activity.

Interestingly, in this current study both stressful factors, $\mathrm{NaCl}$ and mannitol, induced similar membrane damage, which was

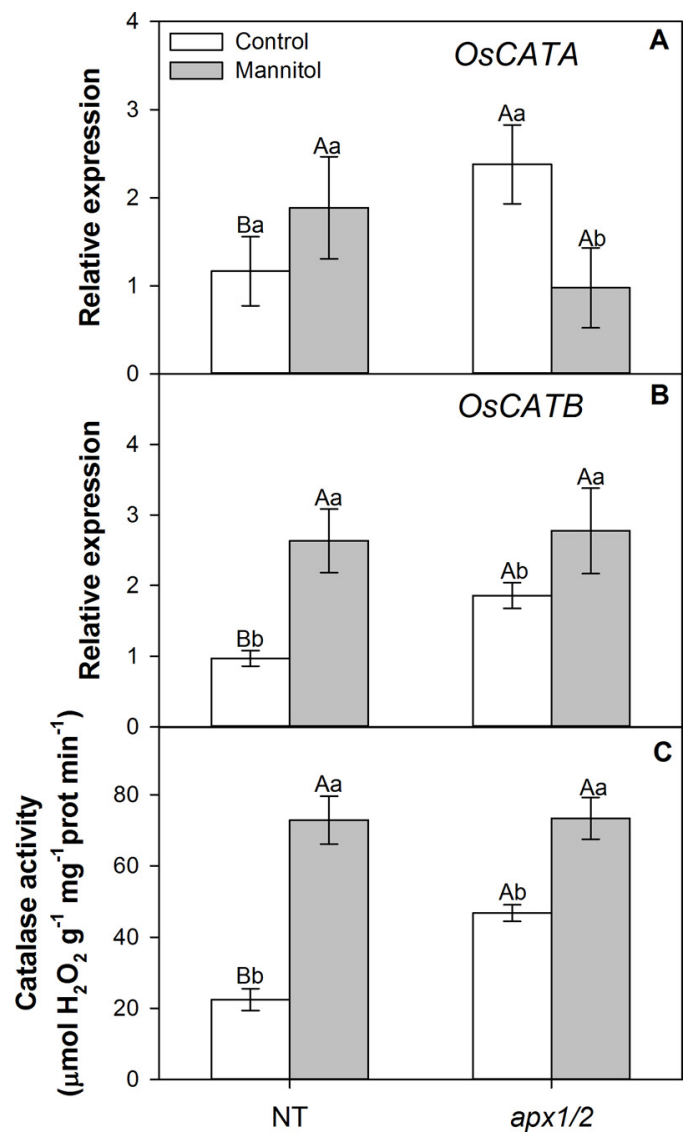

Fig. 9. Transcript levels of OsCATA (A) and OsCATB (B) and CAT activity (C) in roots of NT and apx1/2 plants exposed to mannitol $(268 \mathrm{mM}, \Psi \mathrm{s}=-0.62 \mathrm{MPa})$ solution for eight days. Different capital letters represent significant differences among the NT and apx1/2 plants within different treatments whereas different lowercase letters represent significant differences between treatments, within genotypes. Data are means of four replicates $( \pm \mathrm{SD}$ ) and the averages were compared using the Tukey's test. The relative expression of each APX locus was normalized by the average value obtained from the NT control plants, at a confidence of 0.05 . 

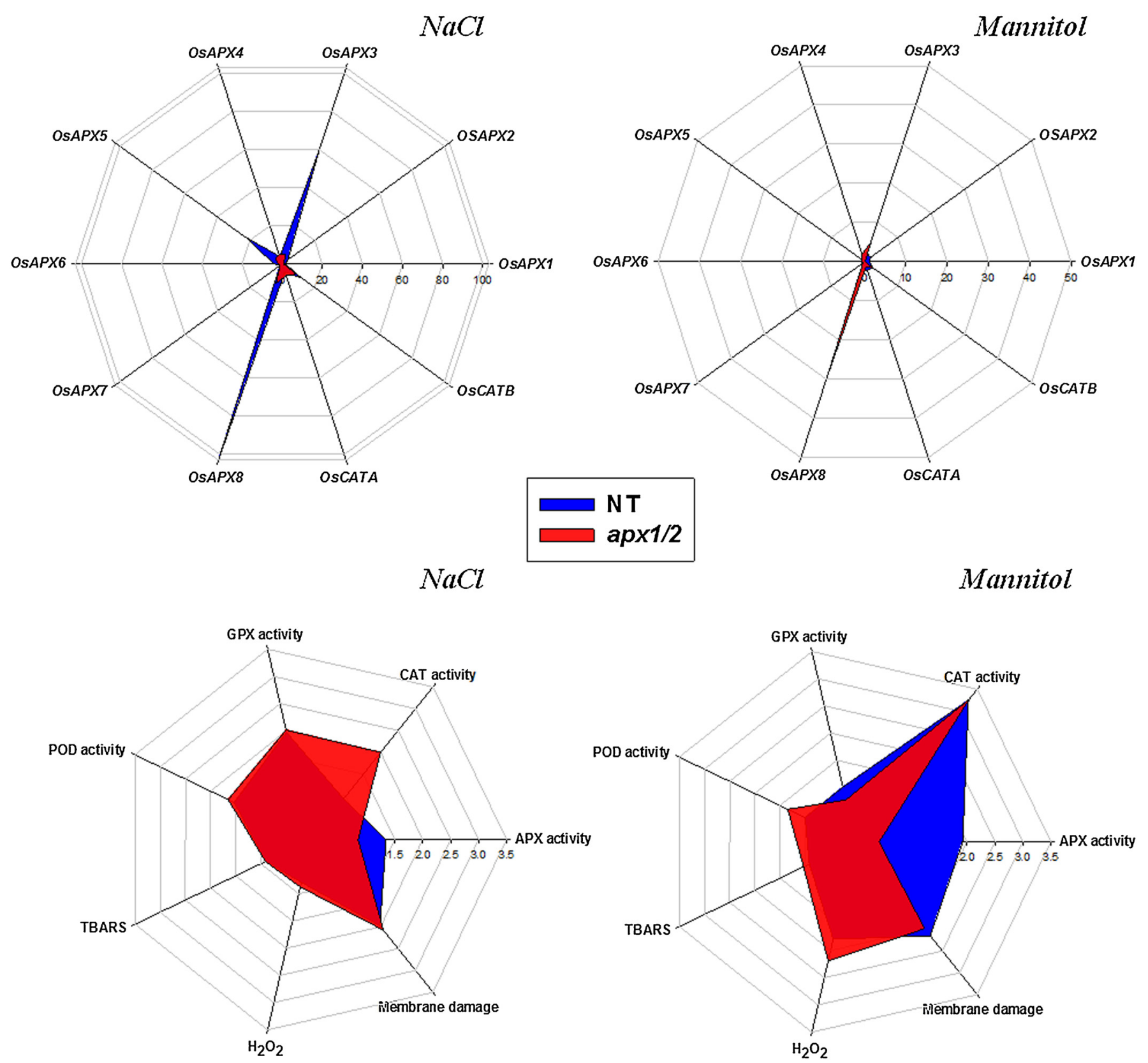

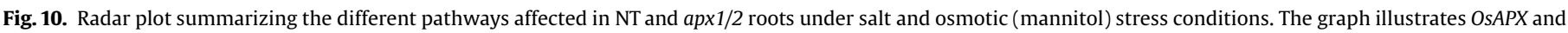

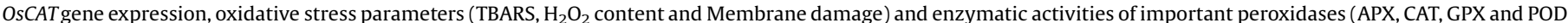

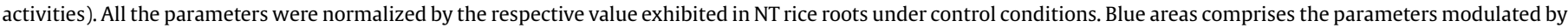

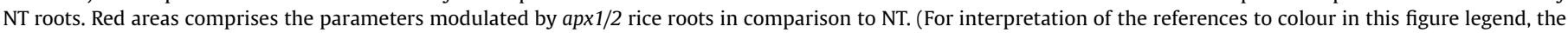
reader is referred to the web version of this article.)

related to absence of oxidative stress, indicated by TBARS accumulation, in roots of both studied genotypes. These results are unexpected and they evidence a complex response. First, these results might suggest that both genotypes displayed efficient and similar protection against ROS accumulation in their roots, each one employing different antioxidant strategies. Second, as TBARS accumulation was not correlated to membrane damage, the obtained data could evidence that the dangerous effects caused on membrane integrity and/or permeability (electrolyte leakage) were not induced directly by ROS but possibly by $\mathrm{NaCl}$ and mannitol per se. Several reports have evidenced that plants display numerous antioxidant redundant (enzymatic and non-enzymatic) pathways to cope with excess ROS generated by abiotic stresses
(Bonifacio et al., 2011; Miller et al., 2007; Rizhsky et al., 2002; Rosa et al., 2010; Sousa et al., 2015).

Some works have evidenced that in certain roots the TBARS accumulation is not frequently well correlated with cell integrity (measured by electrolyte leakage) - (Cavalcanti et al., 2007; de Azevedo Neto et al., 2006; Maia et al., 2013). The elucidation of the mechanisms involved with this apparent discrepancy is lacking. The excess $\mathrm{H}_{2} \mathrm{O}_{2}$ is the initiator for lipid peroxidation reactions via formation of hydroxyl radical by Fenton's reaction (Puppo and Halliwell, 1988). Therefore, the effective action of peroxidases under salinity and osmotic stress could minimize this process by means of $\mathrm{H}_{2} \mathrm{O}_{2}$ scavenging (Baxter et al., 2014; Passardi et al., 2004; Shigeoka and Maruta, 2014). GPX is especially important in this 
process because its activity consumes organic hydroperoxide, blocking the lipid peroxidation chain reactions (Cavalcanti et al., 2007).

Interestingly, in this study each genotype and the two stressful factors induced the expression and activity of different peroxidases to cope with excess $\mathrm{H}_{2} \mathrm{O}_{2}$. These responses were probably related to toxicity avoidance and also to maintain different levels of this signaling molecule, enabling the triggering of distinct peroxidase gene expression (Baxter et al., 2014; Foyer and Noctor, 2015; Shigeoka and Maruta, 2014). Possibly, these responses are part of phenotypic plasticity, redox redundancy and compensatory mechanisms triggered by increased $\mathrm{H}_{2} \mathrm{O}_{2}$ in cytosolic APXs deficient rice roots (Baxter et al., 2014; Bonifacio et al., 2011; Miller et al., 2007; Mittler et al., 2004; Rosa et al., 2010).

Corroborating the above data, both high salinity and osmotic stress induced similar effects on root growth of the two studied genotypes, reinforcing that different physiological, biochemical and molecular mechanisms led to similar phenotypic characteristics. High salinity ( $150 \mathrm{mM} \mathrm{NaCl}$ ) induced significant decrease in root fresh matter of both genotypes and this effect involved clearly osmotic and, possibly in a higher extent, ionic toxicity as revealed by intense $\mathrm{Na}^{+}$accumulation accompanied by strong reduction in $\mathrm{K}^{+} / \mathrm{Na}^{+}$ratios. In opposition, mannitol did not change root biomass in both genotypes, evidencing a stress lesser dangerous than $\mathrm{NaCl}$ and corroborating that ionic component was very harmful to both genotypes. The data presented here reinforce that the high salinity components display distinct and complex responses in rice roots and that the deficiency (knockdown) of cytosolic APXs adds more complexity, as might be visualized in Fig. 10.

In conclusion, high salinity and osmotic stress induce contrasting antioxidant responses at level of change in expression of OsAPX and OsCAT isoforms in non-transformed and cytosolic APXs deficient rice roots. In addition, these two stressful factors also triggered very different modulation in activities of APX, CAT, GPX and POD. All these responses were associated with changes in the $\mathrm{H}_{2} \mathrm{O}_{2}$ levels, suggesting this signaling molecule as a central player. As both stresses induced similar effects in NT and cytosolic APXs deficient roots, in terms of lipid peroxidation, cell integrity and root matter accumulation, it is plausible to conclude that cytosolic APXs deficiency is dispensable to oxidative protection in roots. It is also evident that rice roots deficient in these enzymes are able to display phenotypic plasticity to cope with high salinity and osmotic stress.

\section{Conflicts of interest}

The authors have no conflicts of interest to declare.

\section{Contributions}

JRC conducted all experiments, performed biochemical determinations, and participated of the interpretation and discussion of results. MCLN performed biochemical determinations. FELC interpreted the results and participated of the manuscript writing. MOM performed APX1 and APX2 westernblot analyze and conducted some experiments. DJM performed determinations of qRT-PCR. MMP designed and obtained the transformed plants, supervised the determinations and interpreted the results of qRTPCR. JAGS was the mastermind of the research and wrote the manuscript.

\section{Acknowledgments}

The authors are grateful to Conselho Nacional de Desenvolvimento Científico e Tecnológico (CNPq) and to Coordenação de Aperfeiçoamento Pessoal de Nível Superior (CAPES) for the financial support. J.A.G. Silveira and M. Margis-Pinheiro are CNPq fellowship-honored researchers.

\section{Appendix A. Supplementary data}

Supplementary data associated with this article can be found, in the online version, at http://dx.doi.org/10.1016/j. envexpbot.2016.07.002.

\section{References}

Adem, G., Roy, S.J., Zhou, M., Bowman, J.P., Shabala, S., 2014. Evaluating contribution of ionic, osmotic and oxidative stress components towards salinity tolerance in barley. BMC Plant Biol. 14, 113.

Amako, K., Chen, G.-X.G., Asada, K., 1994. Separate assays specific for ascorbate peroxidase and guaiacol peroxidase and for the chloroplastic and cytosolic isozymes of ascorbate peroxidase in plants. Plant Cell Physiol. 35, 497-504.

Awasthi, Y.C., Beutler, E., Srivastava, S.K., 1975. Purification and properties of human erythrocyte glutathione peroxidase. J. Biol. Chem. 250, 5144-5149.

Baxter, A., Mittler, R., Suzuki, N., 2014. ROS as key players in plant stress signalling. J. Exp. Bot. 65, 1229-1240.

Blum, A., Ebercon, A., 1981. Cell membrane stability as a measure of drought and heat tolerance in wheat. Crop Sci. 21, 43-47.

Bonifacio, A., Martins, M.O., Ribeiro, C.W., Fontenele, A.V., Carvalho, F.E.L., MargisPinheiro, M., Silveira, J.A.G., 2011. Role of peroxidases in the compensation of cytosolic ascorbate peroxidase knockdown in rice plants under abiotic stress. Plant Cell Environ. 34, 1705-1722.

Bradford, M.M., 1976. A rapid and sensitive method for the quantitation of microgram quantities of protein utilizing the principle of protein-dye binding. Anal. Biochem. 72, 248-254.

Cakmak, I., Horst, W.J., 1991. Effect of aluminium on net efflux of nitrate and potassium from root tips of soybean (Glycine max L.). J. Plant Physiol. 138, 400403.

Carvalho, F.E.L., Ribeiro, C.W., Martins, M.O., Bonifacio, A., Staats, C.C., Andrade, C.M. B., Cerqueira, J.V., Margis-Pinheiro, M., Silveira, J.A.G., 2014. Cytosolic APX knockdown rice plants sustain photosynthesis by regulation of protein expression related to photochemistry, Calvin cycle and photorespiration. Physiol. Plant. 150, 632-645.

Cavalcanti, F.R., Santos Lima, J.P.M., Ferreira-Silva, S.L., Viégas, R.A., Silveira, J.A.G. 2007. Roots and leaves display contrasting oxidative response during salt stress and recovery in cowpea. J. Plant Physiol. 164, 591-600.

Choi, W.-G., Toyota, M., Kim, S.-H., Hilleary, R., Gilroy, S., 2014. Salt stress-induced $\mathrm{Ca}_{2}{ }^{+}$waves are associated with rapid, long-distance root-to-shoot signaling in plants. Proc. Natl. Acad. Sci. U. S. A. 111, 6497-6502.

Corpas, F.J., 2015. What is the role of hydrogen peroxide in plant peroxisomes? Plant Biol. 17, 1099-1103.

Davletova, S., Rizhsky, L., Liang, H., Shengqiang, Z., Oliver, D.J., Coutu, J., Shulaev, V., Schlauch, K., Mittler, R., 2005. Cytosolic ascorbate peroxidase 1 is a central component of the reactive oxygen gene network of Arabidopsis. Plant Cell 17, 268-281.

de Azevedo Neto, A.D., Prisco, J.T., Enéas-Filho, J., Abreu, C.E.B., de Gomes-Filho, E. 2006. Effect of salt stress on antioxidative enzymes and lipid peroxidation in leaves and roots of salt-tolerant and salt-sensitive maize genotypes. Environ. Exp. Bot. 56, 87-94.

Flowers, T.J., Munns, R., Colmer, T.D., 2015. Sodium chloride toxicity and the cellular basis of salt tolerance in halophytes. Ann. Bot. 115, 419-431.

Foyer, C.H., Noctor, G., 2005. Redox homeostasis and antioxidant signaling: a metabolic interface between stress perception and physiological responses. Plant Cell 17, 1866-1875.

Foyer, C.H., Noctor, G., 2015. Stress-triggered redox signalling: what's in pROSpect? Plant. Cell Environ. n/a-n/a.

Gupta, H., Cuypers, A., Vangronsveld, J., Clijsters, H., 1999. Copper affects the enzymes of the ascorbate-glutathione cycle and its related metabolites in the roots of Phaseolus vulgaris. Physiol. Plant. 106, 262-267.

Halliwell, B., Foyer, C.H., 1976. Ascorbic acid, metal ions and the superoxide radical. Biochem. J. 155, 697-700.

Havir, E.A., McHale, N.A., 1987. Biochemical and developmental characterization of multiple forms of catalase in tobacco leaves. Plant Physiol. 84, 450-455.

Hernandez, J.J., Corpas, F.J.F., Gomez, M., del Rio, L.A., Sevilla, F., 1993. Salt-induced oxidative stress mediated by activated oxygen species in pea leaf mitochondria. Physiol. Plant. 89, 103-110.

Hoagland, D.R., Arnon, D.I., 1950. The water-culture method for growing plants without soil. Calif. Agric. Exp. Stn. Circ. 347, 1-32.

Hong, C.Y., Hsu, Y.T., Tsai, Y.C., Kao, C.H., 2007. Expression of ascorbate peroxidase 8 in roots of rice (Oryza sativa L:) seedlings in response to $\mathrm{NaCl}$. J. Exp. Bot. 58, 3273-3283.

Hong, C.Y., Chao, Y.Y., Yang, M.Y., Cho, S.C., Huei Kao, C., 2009. $\mathrm{Na}^{+}$but not $\mathrm{Cl}^{-}$or osmotic stress is involved in $\mathrm{NaCl}$-induced expression of glutathione reductase in roots of rice seedlings. J. Plant Physiol. 166, 1598-1606.

Laemli, U.K., 1970. Technique electrophorèse. Nature 227, 680-685.

Liu, Z.J., Guo, Y.K., Bai, J.G., 2010. Exogenous hydrogen peroxide changes antioxidant enzyme activity and protects ultrastructure in leaves of two cucumber ecotypes under osmotic stress. J. Plant Growth Regul. 29, 171-183. 
Møller, I.M., 2001. Plant mitochondria and oxidative stress: electron transport nadph turnover, and metabolism of reactive oxygen species. Annu. Rev. Plant Physiol. Plant Mol. Biol. 52, 561-591.

Małecka, A., Jarmuszkiewicz, W., Tomaszewska, B., 2001. Antioxidative defense to lead stress in subcellular compartments of pea root cells. Acta Biochim. Pol. 48, 687-698.

Maathuis, F.J.M., 2014. Sodium in plants: perception, signalling, and regulation of sodium fluxes. J. Exp. Bot. 65, 849-858.

Maia, J.M., Voigt, E.L., Ferreira-Silva, S.L., Fontenele, A.V., Macêdo, C.E.C., Silveira, J.A G., 2013. Differences in cowpea root growth triggered by salinity and dehydration are associated with oxidative modulation involving types I and III peroxidases and apoplastic ascorbate. J. Plant Growth Regul. 32, 376-387.

Marques, E.C., Freitas, P.A.F., Alencar, N.L.M., Prisco, J.T., Gomes-Filho, E., de Freitas, P. A.F., Alencar, N.L.M., Prisco, J.T., Gomes-Filho, E., 2013. Increased $\mathrm{Na}^{+}$and $\mathrm{Cl}^{-}$ accumulation induced by $\mathrm{NaCl}$ salinity inhibits cotyledonary reserve mobilization and alters the source-sink relationship in establishing dwarf cashew seedlings. Acta Physiol. Plant. 35, 2171-2182.

Miki, D., Shimamoto, K., 2004. Simple RNAi vectors for stable and transient suppression of gene function in rice. Plant Cell Physiol. 45, 490-495.

Miller, G., Suzuki, N., Rizhsky, L., Hegie, A., Koussevitzky, S., Mittler, R., 2007. Double mutants deficient in cytosolic and thylakoid ascorbate peroxidase reveal a complex mode of interaction between reactive oxygen species plant development, and response to abiotic stresses. Plant Physiol. 144, 1777-1785.

Mittler, R., Vanderauwera, S., Gollery, M., Van Breusegem, F., 2004. Reactive oxygen gene network of plants. Trends Plant Sci. 9, 490-498.

Mittova, V., Guy, M., Tal, M., Volokita, M., 2004. Salinity up-regulates the antioxidative system in root mitochondria and peroxisomes of the wild salttolerant tomato species Lycopersicon pennellii. J. Exp. Bot. 55, 1105-1113.

Munné-bosch, S., Queval, G., Foyer, C.H., 2013. The impact of global change factors on redox signaling underpinning stress tolerance 1. Plant Physiol. 161, 5-19.

Munns, R., Gilliham, M., 2015. Salinity tolerance of crops - what is the cost? New Phytol. 208, 668-673.

Nakano, Y., Asada, K., 1981. Hydrogen peroxide is scavenged by ascorbato specific peroxidase in spinach chloroplasts. Plant Cell Physiol. 22, 867-880.

Passardi, F., Penel, C., Dunand, C., 2004. Performing the paradoxical: how plant peroxidases modify the cell wall. Trends Plant Sci. 9, 534-540.

Petrov, V.D., Van Breusegem, F., 2012. Hydrogen peroxide-a central hub for information flow in plant cells. AoB Plants 2012, pls014.

Pierik, R., Testerink, C., 2014. The art of being flexible: how to escape from shade, salt and drought. Plant Physiol. 166, 5-22.

Pnueli, L., Liang, H., Rozenberg, M., Mittler, R., 2003. Growth suppression, altered stomatal responses, and augmented induction of heat shock proteins in cytosolic ascorbate peroxidase (Apx1)-deficient Arabidopsis plants. Plant J. 34, 187-203.
Puppo, A., Halliwell, B., 1988. Formation of hydroxyl radicals from hydrogen peroxide in the presence of iron. Is haemoglobin a biological Fenton reagent? Biochem. J. 249, 185-190.

Rizhsky, L., Hallak-Herr, E., Van Breusegem, F., Rachmilevitch, S., Barr, J.E., Rodermel, S., Inzé, D., Mittler, R., 2002. Double antisense plants lacking ascorbate peroxidase and catalase are less sensitive to oxidative stress than single antisense plants lacking ascorbate peroxidase or catalase. Plant J. 32, 329-342.

Rosa, S.B., Caverzan, A., Teixeira, F.K., Lazzarotto, F., Silveira, J.A.G., Ferreira-Silva, S.L. Abreu-Neto, J., Margis, R., Margis-Pinheiro, M., 2010. Cytosolic APx knockdown indicates an ambiguous redox responses in rice. Phytochemistry 71, 548-558.

Roy, S.J., Negrão, S., Tester, M., 2014. Salt resistant crop plants. Curr. Opin. Biotechnol. $26,115-124$

Sewelam, N., Jaspert, N., Van Der Kelen, K., Tognetti, V.B., Schmitz, J., Frerigmann, H., Stahl, E., Zeier, J., Van Breusegem, F., Maurino, V.G., 2014. Spatial $\mathrm{H}_{2} \mathrm{O}_{2}$ signaling specificity: $\mathrm{h}_{2} \mathrm{O}_{2}$ from chloroplasts and peroxisomes modulates the plant transcriptome differentially. Mol. Plant 7, 1191-1210.

Shigeoka, S., Maruta, T., 2014. Cellular redox regulation, signaling, and stress response in plants. Biosci. Biotechnol. Biochem. 78, 1457-1470.

Sousa, R.H.V., Carvalho, F.E.L., Ribeiro, C.W., Passaia, G., Cunha, J.R., Lima-Melo, Y., Margis-Pinheiro, M., Silveira, J.A.G., 2015. Peroxisomal APX knockdown triggers antioxidant mechanisms favourable for coping with high photorespiratory $\mathrm{H}_{2} \mathrm{O}_{2}$ induced by CAT deficiency in rice. Plant. Cell Environ. 38, 499-513.

Tabata, R., Sumida, K., Yoshii, T., Ohyama, K., Shinohara, H., Matsubayashi, Y., 2014. Perception of root-derived peptides by shoot LRR-RKs mediates systemic Ndemand signaling. Science 346, 343-346.

Teixeira, F.K., Menezes-Benavente, L., Margis, R., Margis-Pinheiro, M., 2004. Analysis of the molecular evolutionary history of the ascorbate peroxidase gene family: inferences from the rice genome. J. Mol. Evol. 59, 761-770.

Teixeira, F.K., Menezes-Benavente, L., Galvão, V.C., Margis, R., Margis-Pinheiro, M., 2006. Rice ascorbate peroxidase gene family encodes functionally diverse isoforms localized in different subcellular compartments. Planta 224, 300-314.

Towbin, H., Staehelin, T., Gordon, J., 1979. Electrophoretic transfer of proteins from polyacrylamide gels to nitrocellulose sheets: procedure and some applications. Proc. Natl. Acad. Sci. U. S. A. 76, 4350-4354.

Zhang, J., Zhang, X., 1994. Can early wilting of old leaves account for much of the ABA accumulation in flooded pea plants? J. Exp. Bot. 45, 1335-1342.

Zhou, M., Diwu, Z., Panchuk-Voloshina, N., Haugland, R.P., 1997. A stable nonfluorescent derivative of resorufin for the fluorometric determination of trace hydrogen peroxide: applications in detecting the activity of phagocyte NADPH oxidase and other oxidases. Anal. Biochem. 253, 162-168.

Zhu, J.-K., 2002. Salt and drought stress signal transduction in plants. Annu. Rev. Plant Biol. 53, 247-273. 